\title{
Alterations of actin cytoskeleton and arterial protein amounts in patients with obstructive jaundice.
}

\section{Hongqian Wang}

second military medical university

Xiaoyan Meng

second military medical university

Mo Chen

second military medical university

Jinming Zhang

second military medical university

\section{Baohua Zhang}

second military medical university

Feixiang Wu ( $\nabla$ shawn9506@126.com )

second military medical university, eastern hepatobiliary surgical hospital. https://orcid.org/00000003-1149-3894

\section{Research article}

Keywords: Vascular hypo-reactivity; obstructive jaundice; proteomics; artery; hemodynamic changes.

Posted Date: June 27th, 2019

DOI: https://doi.org/10.21203/rs.2.10394/v1

License: (c) (1) This work is licensed under a Creative Commons Attribution 4.0 International License.

Read Full License 


\section{Abstract}

Background: Vascular hypo-responsiveness to vasopressors in patients with obstructive jaundice (OJ) is a common anesthetic event, which leads to perioperative complications and increased mortality. The cause of this clinical issue remains unclear. Here, changes in the artery of $\mathrm{OJ}$ patients were assessed by proteomic analysis. Methods: Ten patients with OJ due to bile duct or pancreatic head neoplasms were enrolled, alongside ten chronic cholecystitis or liver hemangioma cases forming the controls group. Vascular reactivity was measured before anesthesia on the day of surgery. Artery samples near or surrounding the removed tumor tissues were collected and evaluated by 2-dimensional electrophoresis. Proteins with differential expression were detected by MALDI-TOF mass spectrometry, with immunoblot confirmation. Results: Vascular hypo-reactivity in OJ cases as well as suppressed aortic response to vasoactive products were evidenced. We also found that actin cytoskeleton and several actin-binding proteins were up- or down-regulated in the artery of OJ patients. Conclusion: The newly detected regulated proteins prompt future functional investigations to unveil the mechanisms of vascular hyporeactivity in patients with obstructive jaundice. Trial registration $₫$ Australia New Zealand Clinical Trials Registry; Research Register Number, U1111-1124-2612; Principal investigator, Feixiang Wu; Registered Data, 09/2011). Key words $₫$ vascular hypo-reactivity; obstructive jaundice; proteomics; artery; hemodynamic changes.

\section{Background}

Obstructive jaundice $(\mathrm{OJ})$ is a frequent clinical manifestation, which is attributed to gallstones, malignant tumors and other ailments. Most patients suffering from OJ require surgery. However, perioperative complications and mortality have higher incidence rates in $\mathrm{OJ}$ cases compared with non-jaundice patients(1). This is mainly due to perioperative hypotension, acute renal failure and other complications caused by endotoxemia(2). What's more, hypotension is a highly rated and prominent clinical mark for anesthesia in OJ during operation(3).

Our previous study found that impaired arterial baroreflex sensitivity may play a role in enhancing susceptibility to the well-known perioperative complications encountered in OJ patients during anesthesia(4), consistent with other studies(5). However, the molecular mechanisms behind vascular function change in $\mathrm{OJ}$ remain unclear, and morbidity and overall mortality of low blood pressure, renal failure or multiple organ dysfunction syndrome cannot be currently improved, unless suitable treatment for vascular injury in jaundice is developed.

In the current work, changes in the artery of OJ patients were evaluated. This study aimed to assess the arterial proteome for differentially expressed proteins in various databases, to provide insights into the molecular mechanisms underpinning vascular hypo-responsiveness in patients with OJ.

\section{Methods}




\section{Patients}

Eligibility criteria were based on our previous work(4). This trial had approval from the Shanghai ethics committee (Register Number: ACTRN12611000980932). All subjects participating in the current trial provided signed informed consent. The trial was registered prior to patient enrollment in ANZCTR (Australia New Zealand Clinical Trials Registry; Research Register Number, U1111-1124-2612; Principal investigator, Feixiang Wu; Registered Data, 09/2011). Ten patients with obstructive jaundice due to bile duct or pancreatic head neoplasms were enrolled, along ten chronic cholecystitis or liver hemangioma cases forming the control group. The patients assessed had American Society of Anesthesiologists physical statuses I and II, respectively, and were 40-70 years old. All participating patients were scheduled for elective surgery for the underlying diseases from June 2011 to December 2011 in Eastern Hepatobiliary surgical hospital, Shanghai, China.

Exclusion criteria comprised: (1) age $>70$ years or <20 years; (2) pronounced obesity (body mass index $>30 \mathrm{~kg} / \mathrm{m}^{2}$ ); (3) previous cardiovascular, pulmonary, or kidney disease; (4) hepatic encephalopathy, psychiatric disease, or neuropathology; (5) acid-base balance alteration, blood electrolyte imbalance, diabetes, sepsis, or overt weight loss resulting from cancer.

\section{Vascular reactivity Measurement}

Vascular reactivity was measured prior to anesthesia the day of surgery. Upon arrival to the operating room following fasting (8 to 10h), electrocardiography monitoring (lead II), finger pulse oximetry and noninvasive blood pressure assessment were carried out. Under local anesthesia, the left radial artery was punctured and catheterized, and connected via a sensor to a waveform analyzer (Vigileo system, Edwards life sciences, USA). Parameters were set with no adjustment, for continuous monitoring of cardiac output (CO), cardiac output index (Cl), each-volume (SV), stroke volume index (SVI) and stroke volume variation (SVV). After puncturing the right internal jugular vein and indwelling a three-cavity central venous catheter under local anesthesia, central venous pressure (CVP) was simultaneously recorded. Body circulation resistance (SVR) and body circulation resistance index (SVRI) were calculated by inputting the obtained CVP values. Recorded values were averaged from three separate measurements. Ringer lactate solution was continuously instilled at $2 \mathrm{ml} / \mathrm{kg} / \mathrm{h}$. The patients were placed in the supine position for 20 minutes or more after entering the surgical room, and vascular reactivity was observed upon tension relief. After recording baseline values for mean arterial pressure (MAP), HR, CO, Cl, SVR and SVRI, continuous infusion of increasing concentrations of noradrenaline for 5 min (30 and $60 \mathrm{ng} \cdot \mathrm{kg}^{-1} \mathrm{~min}^{-1}$ ) was performed, with a 20-minute interval between the two concentrations to allow recovery. Systolic blood pressure did not exceed $160 \mathrm{mmHg}$ at the maximum dose. Stable for 3 minutes during each administration, systolic blood pressure and the heart rate returned to pre-test levels, fluctuating up and down within $5 \%$.

\section{Preparation of Total Protein Extracts}

Artery samples near or surrounding the removed tissues were collected. About $100 \mathrm{mg}$ of these samples were washed with cold PBS buffer three times. After PBS removal, $1 \mathrm{ml}$ of lysis buffer $(9.5 \mathrm{M}$ 
Urea, 65 mM DTT, 4\% CHAPS and 0.2\% IPG buffer, mixed with enzyme inhibitors at 50:1 v/v) was added. The samples were then homogenized with a Dounce homogenizer after vertexing. Next, ultrasonication of the specimens was performed 5 times at 15-second intervals on ice (80W, 10 seconds). Supernatants were collected and stored at $-80^{\circ} \mathrm{C}$ after centrifugation $\left(12,000 \mathrm{~g}, 4^{\circ} \mathrm{C}\right)$ for 45 minutes. Quantitative analysis of total protein in artery samples was performed with Bio-Rad protein assay reagents.

\section{Two-Dimensional Electrophoresis (2-DE)}

Proteins $(100 \mu \mathrm{g})$ were firstly resolved by isoelectrofocusing (IEF) with gel strips measuring pH values between 3 and 10 based on a non-linear gradient (IPG strip, $18 \mathrm{~cm}$; GE Healthcare, Waukesha, WI, USA). Strip rehydration was carried out in a Protein IEF Cell (GE Healthcare) in the passive (4h) and active (12h) modes at room temperature. Simultaneous IEF was carried out on an Ettan IPGphor Isoelectric Focusing system as follows: (a) $30 \mathrm{~V}$ for $12 \mathrm{~h}$; (b) voltage gradient to $500 \mathrm{~V}$ in $1 \mathrm{~h}$; (c) gradient to $1000 \mathrm{~V}$ in $1 \mathrm{~h}$; (d) gradient to $8000 \mathrm{~V}$ in $8 \mathrm{~h}$; (e) $500 \mathrm{~V}$ for $4 \mathrm{~h}$. Next, IPG strips were placed onto vertical $12.5 \%$ polyacrylamide gels in an Ettan-DALT Six system (GE Healthcare). Second-dimension SDS-PAGE was performed on a Hofer SE 600 system (GE Healthcare) at $5 \mathrm{~W} /$ gel for 30 min followed by $180 \mathrm{~W}$ for $4 \mathrm{~h}$. Protein spots were detected after silver staining on an UMax Powerlook 2110XL scanner (GE Healthcare).

\section{Trypsin Digestion and Gel Extraction}

Spots of interest were excised from Coomassie Brilliant Blue treated gels after 2 Milli-Q water (15 min) and $4 \mathrm{NH} 4 \mathrm{HCO} 3$ (25 mM in 50\% acetonitrile; 30 minutes) washes. After washing, the gel pieces were submitted to acetonitrile $(50 \mathrm{~mL})$ dehydration until opacity and further placed at $60^{\circ} \mathrm{C}$ to total dryness; rehydration was carried out in $50 \mathrm{mM} \mathrm{NH} 4 \mathrm{HCO} 3$. Next, the samples were digested with trypsin (12.5 $\mathrm{ng} / \mathrm{mL}$; Promega, Madison, USA) in 10-mL reactions. The samples were chilled on ice for 45 min followed by addition of $25 \mathrm{mM} \mathrm{NH} 4 \mathrm{HCO} 3$ and overnight incubation $\left(37^{\circ} \mathrm{C}\right)$. After centrifugation, supernatants were submitted to 3 extractions with $50 \%$ acetonitrile containing $0.1 \%$ trifluoroacetic acid. The resulting mixtures were vacuum-dried. In MALDI-TOF/TOF, peptide elution was performed with 0.7 mL a-cyano-4hydroxy-cinnamic acid (Sigma, St. Louis, MO, USA) in $0.1 \%$ trifluoroacetic acid/50\% acetonitrile.

\section{Mass Spectrometry}

A 5800 MALDI TOF/TOF analyzer (Applied Biosystem, Framingham, MA, USA) was employed for assessments. Mass spectrum (m/z 800-4000) acquisition was in the positive ion reflector mode. The top 20 ions in terms of intensity were submitted to MS/MS sequencing in the $2 \mathrm{kV}$ mode. The NCBI protein database was queried for matched MS/MS spectra by Matrix Science (http://www.matrixscience.com) for the identification of proteins: taxonomy, Green Plants; peptide tolerance, 1.2 Da; MS/MS tolerance, 0.6 Da; 1 incomplete cleavage allowed; modification, methionine oxidation. Based on MASCOT probability assessment $(P<0.05)$, significant hits were used for protein identification. The identified proteins were examined for sub-cellular localization and function with TargetP (http://www.cbs.dtu.dk/services/TargetP/) or PSORT (http://psort.hgc.jp/). Further, potentially related 
pathways and biochemical reactions were queried in Uniprot (http://www.uniprot.org/) and Genome-Net (http://www.genome.ad.jp/kegg/).

\section{Western Blot}

Aorta segment lysis was performed with chilled lysis buffer in presence of protease inhibitors. Lysate centrifugation was carried out at $12,000 \mathrm{rpm}$ for $15 \mathrm{~min}$ at $4^{\circ} \mathrm{C}$. Total protein in the supernatant was quantitated with a BSA assay kit (P0006, Beyotime, Jiangsu, China). Protein separation was performed by $10 \%$ sodium dodecyl sulfate polyacrylamide gel electrophoresis (SDS-PAGE), and protein bands were electro-transferred onto polyvinylidene difluoride (PVDF) membranes. The samples were incubated overnight at $4^{\circ} \mathrm{C}$ with anti-tropomyosin $\beta$, anti-transgelin, anti-annexin, anti-gelsolin, anti-HSP-27, anticofilin-1 and anti-GAPDH (1:1000; Abcam, Cambridge, UK) primary antibodies. Further incubation was performed with goat anti-mouse or anti-rabbit secondary antibodies (1:10,000; Santa Cruz Biotechnology, USA) for $1 \mathrm{~h}$ in ambient conditions. Development was carried out with the BeyoECL kit (Beyotime, China) and a Tanon 5200 system.

\section{Statistical Analysis}

Spot intensities for differentially expressed proteins in D gels were obtained from three independent experiments. One-way analysis of variance and Duncan's multiple range test were employed for comparisons. $\mathrm{P}<0.05$ was deemed statistically significant.

\section{Results}

\section{General conditions}

Age, gender distribution, height, weight and BSA were comparable in both groups. Serum total bilirubin and bile acid amounts were markedly elevated in patients compared with controls (all $P<0.01$; Table 1 ).

\section{Vascular reactivity}

Baseline values for hemodynamic data such as MAP, heart rate (HR), CVP, CO, Cl, SVR and SVRI were comparable in both groups (Table 2). Increases in dose-related MAP, SVR and SVRI were observed in both groups compared with baseline values (Figure 1). After continuous infusion of $30 \mathrm{ng} \cdot \mathrm{kg}^{-1} \mathrm{~min}^{-1}$ norepinephrine for $5 \mathrm{~min}, \mathrm{MAP}$ increase in jaundice patients (from $80.7 \pm 5.9 \mathrm{mmHg}$ to $85.5 \pm 6.6 \mathrm{mmHg}$ ) was lower than that of the non-jaundice group (from $84.1 \pm 6.7 \mathrm{mmHg}$ to $94.5 \pm 7.4 \mathrm{mmHg}, \mathrm{p}<0.05$ ). Similarly, after continuous pumping of $60 \mathrm{ng} \cdot \mathrm{kg}^{-1} \mathrm{~min}^{-1}$ norepinephrine for $5 \mathrm{~min}$, MAP increase in patients with jaundice was significantly lower than of the non-jaundice group (from $81.7 \pm 6.3 \mathrm{mmHg}$ to $88.8 \pm 6.5$ $\mathrm{mmHg}$ and from $85.7 \pm 6.9 \mathrm{mmHg}$ to $102.3 \pm 8.4 \mathrm{mmHg}$, respectively; $\mathrm{p}<0.05)$.

After continuous pumping of norepinephrine, SVR increases were less pronounced in the jaundice group (from $1105.45 \pm 119.01$ dyn.s.cm ${ }^{-5} \mathrm{~m}^{2}$ to $1181.09 \pm 141.90$ dyn.s. $\mathrm{cm}^{-5} \mathrm{~m}^{2}$ at a dose of $30 \mathrm{ng} . \mathrm{kg}^{-1} \mathrm{~min}^{-1}$; from $1110.86 \pm 127.86$ dyn.s.cm ${ }^{-5} \mathrm{~m}^{2}$ to $1288.62 \pm 154.71$ dyn.s. $\mathrm{cm}^{-5} \mathrm{~m}^{2}$ at $60 \mathrm{ng} . \mathrm{kg}^{-1} \mathrm{~min}^{-1}, \mathrm{p}<0.05$ ) in 
comparison with the non-jaundice group (from $1135.75 \pm 95.80$ dyn.s. $\mathrm{cm}^{-5} \mathrm{~m}^{2}$ to $1289.96 \pm 139.04$ dyn.s.cm ${ }^{-5} \mathrm{~m}^{2}$ at a dose of $30 \mathrm{ng} . \mathrm{kg}^{-1} \mathrm{~min}^{-1}$; from $1135.75 \pm 101.47$ dyn.s. $\mathrm{cm}^{-5} \mathrm{~m}^{2}$ to $1472.01 \pm 155.63$ dyn.s. $\mathrm{cm}^{-5} \mathrm{~m}^{2}$ at $\left.60 \mathrm{ng} . \mathrm{kg}^{-1} \mathrm{~min}^{-1}, \mathrm{p}<0.05\right)$. Similarly, SVRI increases were less pronounced in the jaundice group (from $1805.29 \pm 276.31$ dyn.s.cm ${ }^{-5} \mathrm{~m}^{2}$ to $1930.89 \pm 329.48$ dyn.s. $\mathrm{cm}^{-5} \mathrm{~m}^{2}$ at a dose of $30 \mathrm{ng} . \mathrm{kg}^{-1} \mathrm{~min}^{-}$ ${ }^{1}$; from $1813.52 \pm 281.06$ dyn.s.cm $\mathrm{cm}^{-5} \mathrm{~m}^{2}$ to $2105.65 \pm 352.91$ dyn.s. $\mathrm{cm}^{-5} \mathrm{~m}^{2}$ at $60 \mathrm{ng} . \mathrm{kg}^{-1} \mathrm{~min}^{-1}, \mathrm{p}<0.05$ ) in comparison with the non-jaundice group (from $1911.25 \pm 333.43$ dyn.s. $\mathrm{cm}^{-5} \mathrm{~m}^{2}$ to $2172.80 \pm 426.08$ dyn.s.cm ${ }^{-5} \mathrm{~m}^{2}$ at a dose of $30 \mathrm{ng} . \mathrm{kg}^{-1} \mathrm{~min}^{-1}$; from $1912.70 \pm 349.62$ dyn.s. $\mathrm{cm}^{-5} \mathrm{~m}^{2}$ to $2477.27 \pm 463.41$ dyn.s. $\mathrm{cm}^{-5} \mathrm{~m}^{2}$ at $\left.60 \mathrm{ng} \cdot \mathrm{kg}^{-1} \mathrm{~min}^{-1}, \mathrm{p}<0.05\right)$. There were no statistical differences in $\mathrm{CO}$ and $\mathrm{Cl}$ changes between the patient and control groups.

\section{Proteomics findings}

In order to determine quantitative expression differences in proteins between obstructive jaundice and non-jaundice patients, the proteomic profiles of both groups were analyzed. In this comparison, thirtythree differentially expressed spots were identified by 2-DE image analysis (Figure.2).

\section{Bioinformatics findings}

A total of 24 proteins with differential expression between obstructive jaundice and non-jaundice patients were identified by MS/MS. They included 17 upregulated and 7 downregulated proteins (Table 2).

As described by Bevan et al.(6), the above proteins were grouped by functional category. They belonged to the categories of Cytoskeleton, Metabolism, Signal transduction, Transport, Proliferation/Apoptosis/Differentiation, Stress response, DNA repair, Transcription regulation, Cell adhesion and Immune response, respectively. An important fraction of proteins were associated with the cytoskeleton (33.33\%), and 16.67\% were involved in metabolism (Figure 3).

\section{Confirmation of proteomics findings}

We used Western blot to confirm seven actin or actin related proteins in the cytoskeleton signaling pathway. As shown in Figure 4, the expression levels of actin, tropomyosin $\beta$, transgelin, annexin, gelsolin, HSP-27 and cofilin-1 were in accordance with proteomics data.

\section{Discussion}

Previous studies reported vascular hypo-reactivity in $\mathrm{OJ}$ cases as well as reduced aortic response to vasoactive products; further animal studies revealed that this effect was attributed to deregulated expression of receptors or related proteins in vascular smooth muscle cells and endothelial cells. To confirm this clinical phenomenon, we compared vascular reactivity to norepinephrine in obstructive jaundice and non-obstructive jaundice patients by non-invasive and invasive monitoring methods. Then, differential protein expression was assessed in blood vessels of these two groups by proteomic analysis. 
In the current clinical trial, we identified dose dependent hemodynamic changes after norepinephrine infusion, and changes in HR, CVP, CO and $\mathrm{Cl}$ showed no marked differences between the OJ and control groups, reflecting similar cardiac contractility and blood volume in both groups. What's more, differential responses of MAP, SVR and SVRI to the vasoconstrictor were found in both groups, confirming vascular hyporeactivity in the artery and aorta of jaundice patients to certain vasoactive agents. Comparison of proteomic profiles between artery samples from jaundice and non-jaundice patients revealed a total of 24 differentially expressed proteins, with around $50 \%$ related to cytoskeleton or metabolism. Among them, actin cytoskeleton signaling represented a pathway dysregulated in obstructive jaundice, with statistical significance. We further investigated seven abnormally expressed proteins which were closely related to vascular hyporeactivity of jaundice patients, independently confirming their expression trends by immunoblot.

Functional annotation of proteins with differential expression in jaundice patients revealed approximately $33 \%$ were associated with the cytoskeleton, while $17 \%$ were involved in metabolism. These findings validate our hypothesis, since lower reactivity occurs during cytoskeleton structure modifications in VSMCs and/or endothelial cells(7), as well as changes in cellular metabolism. Actin cytoskeleton signaling emerging from the above proteomics data depicting proteins with differential expression in OJ, seemed to have an important function in vascular hyporeactivity in jaundice patients. These findings suggested that vascular hyporeactivity in patients with obstructive jaundice is probably due to an impairment of actin-mediated muscle contractile activity. The contractile system of vascular smooth muscle comprises thin and thick filaments made of actin and myosin, respectively(8). Actin polymerization and cytoskeletal dynamics regulate force development in vascular smooth muscle, which results in blood pressure and blood flow regulation(9). In a-actin deficient mice, vascular contractility and blood pressure homeostasis are impaired, with compromised vascular contractility, decreased blood pressure, and reduced blood flow after a-actin gene transcription in the smooth muscle is inactivated(10).

As shown above, actin was impaired in the artery of OJ patients; meanwhile, several actin-binding proteins were also downregulated in OJ patients. Tropomyosin is known to bind actin filaments and interact with multiple actin binding proteins, playing significant roles in muscle contraction and thinfilament assembly in both muscle and non-muscle cells. Greenberg MJ demonstrated that the intrastrand reinforcement by smooth muscle tropomyosin increases persistence length by 1.5 -fold(11). The conserved periodic sites of tropomyosin are also important in regulating actin-myosin interaction that produces force generation between actin filaments, leading to contractions.(12) Hence, beta-tropomyosin upregulation in the present study in blood vessels may probably lead to vascular hyporeactivity in $\mathrm{OJ}$ patients. According to the above results, annexin A2 and A5 were also upregulated in OJ. Annexin represents a calcium-dependent phospholipid-binding protein that contributes to the exocytosis of intracellular proteins(13), and modulates several cell events, including motility, membrane-associated protein complex binding to the actin cytoskeleton, endocytosis and fibrinolysis(14). Recombining actomyosin, annexins, and caveolar fats in presence of calcium ions generates a well-arranged precipitate; such arrangement ensures efficient transmission of contractile activity in smooth muscle cells(15). Another increased protein was gelsolin, a calcium-regulated actin filament severing and 
nucleating protein found in many cell types which is involved in various cellular processes, including regulation of actin dynamics, cell motility, control of apoptosis and cellular signal transduction.

Knockdown of the gelsolin-like protein CapG in pulmonary arterial smooth muscle cells (PASMCs) causes reduced proliferation, enhanced apoptosis and cell cycle arrest, while its downregulation attenuates pulmonary hypertension. This indicates CapG contributes to pulmonary vascular remodeling(16). CapG promotes monomer assembly into filaments and also severs existing filaments. Further studies to elucidate the physiological role of gelsolin are under way in our laboratory. Of note, stress resistance and actin organization related heat shock protein (HSP) was also overexpressed in OJ patients. HSP regulates the actin cytoskeleton in differentiated smooth muscle cells due to elevated amounts of this protein as well as co-localization with contractile proteins(17). Stretch causes remarkable structural disruption of the actin cytoskeleton and decreases the F/G-actin ratio in bladder smooth muscle cells (BSMCs) in vitro with HSP27 over-expression and knock-down, indicating an important role for HSP27 in bladder smooth muscle contraction(18). In smooth muscle samples after permeabilization, agonist-associated contraction is suppressed by anti-HSP27 antibodies, reducing HSP27 phosphorylation inhibits vasoconstriction caused by angiotensin II(19). In the present study, HSP27 was decreased in OJ patients as assessed by proteomic analysis and further confirmed by Western blot. The last upregulated actin binding protein in OJ was cofilin-1. Actin depolymerizing factors (ADFs)/cofilins are widely found in eukaryotes, with diverse functions based on highly complex associations with both monomeric and filamentous actins(20). Cofilin binds to F-actin and is involved in the regulation of actin cytoskeleton dynamics and cell morphology(21). Transgelin is an actin-binding protein but was lowly expressed in OJ patients. This protein is also known as smooth muscle 22 a (SM22a). It is specifically found in the contractile smooth muscle of mammalians alongside additional differentiation markers such as a-actin, calponin and smooth muscle myosin. In SM22a(-/-) mice, contraction of aortic rings in response to angiotensin II (Ang II) is significantly decreased in vitro, and extracellular signal-regulated kinase 1/2 (ERK1/2) phosphorylated levels are reduced, suggesting SM22a promotes Angll-associated contraction via maintenance of the ERK1/2 pathway(22), Meanwhile, actin amounts are reduced by $10-25 \%$ in vessels from transgelin knockout mice(23). In OJ patients, whether transgelin downregulation occurs through actin or actin upregulation is through transgelin requires further investigation.

Besides actin binding proteins, proteins related to actin regulation were decreased in the artery of $\mathrm{OJ}$ patients. LIM and SH3 domain protein 1 (LASP) has a critical function in regulating the dynamic activities of the actin cytoskeleton. Agonist-associated LASP1 phosphorylation alterations might also modulate actin-related ion transport in parietal cells as well as other secretory epithelial cells expressing high Factin levels. This novel actin-binding protein could control a pathway contributing to cell cytoskeleton organization(24). Adapter proteins, such as Sorbin and SH3 domain-containing protein 2 (SORBS), play roles in signaling complex assembly, linking ABL kinases and the actin cytoskeleton. SORBS2 is an adapter protein that functions in cytoskeletal organization, cell adhesion and signaling pathways.

Other non-actin related proteins significantly altered in $\mathrm{OJ}$ included vimentin, one of the main structural constituents of IFs in multiple cells, plays a critical role in essential cell functions, including contractility, migration, stiffness, stiffening and division(25). Vimentin-deficient cells exhibit reduced contractility, 
indicating vimentin IFs are essential in preserving mechanical interactions among cells. Considering the apparent upregulation of this protein, we also propose that it may have a critical function in vascular hyporeactivity in OJ, which deserves further animal experiments.

\section{Conclusions}

The present study confirmed vascular hyporeactivity to norepinephrine in $0 \mathrm{~J}$ patients, and several deregulated proteins were further determined by proteomic analysis. The present findings suggested that several actin or actin-related proteins in the actin cytoskeleton signaling pathway may probably be largely involved in vascular hypo-reactivity in OJ patients. Although with several limitations, for instance, smooth muscle cells and epithelial cells of the artery were not separated in this analysis, we believe that this study provides valuable evidence and directions for further investigations.

\section{Abbreviations}

OJ: obstructive jaundice, ANZCTR: Australia New Zealand Clinical Trials Registry, CO: cardiac output, Cl: cardiac output index, SV: each-volume, SVI: stroke volume index, SVV: stroke volume variation, CVP: central venous pressure, SVR: circulation resistance, SVRI: body circulation resistance index, SDS-PAGE: sodium dodecyl sulfate polyacrylamide gel electrophoresis, PVDF: protein bands were electro-transferred onto polyvinylidene difluoride.

\section{Declarations}

\section{Ethics approval and consent to participate.}

This trial had approval from the Shanghai ethics committee (Register Number: ACTRN12611000980932). All subjects participating in the current trial provided signed informed consent. All experimental procedures involving animals were approved by the Animal Ethics Committee of Second Military Medical University, and complied with the Guide for the Care and Use of Laboratory Animals published by the National Institutes of Health (NIH Publication No. 85-23, revised 1996).

\section{Consent for publication.}

Not applicable.

\section{Availability of data and materials.}

The datasets used and/or analyzed during the current study are available from the corresponding author on reasonable request.

\section{Competing interests.}

The authors declare that they have no competing interests. 


\section{Funding.}

Funding: This study was supported by grants from the National Natural Science Foundation of China (No.81671082).

\section{Authors' contributions}

Authors' contributions: Fei-xiang Wu. designed the study. Bao-hua Zhang wrote most of the article. Hongqian Wang and Xiao-yan Meng contributed to the data collection and revised the article, Mo Chen and Jinmin Zhang contributed to the data collection. All authors read and approved the final manuscript.

\section{Acknowledgements}

The authors thank Han Wang, M.D. for their contributions to data analysis.

\section{References}

1. Sewnath ME, Karsten TM, Prins MH, Rauws EJ, Obertop H, Gouma DJ. A meta-analysis on the efficacy of preoperative biliary drainage for tumors causing obstructive jaundice. Ann Surg. 2002; 236(1):17-27.

2. Binah O, Bomzon A, Blendis LM, Mordohovich D, Better OS. Obstructive jaundice blunts myocardial contractile response to isoprenaline in the dog: a clue to the susceptibility of jaundiced patients to shock? Clin Sci (Lond). 1985; 69(6):647-653.

3. Green J, Better OS. Systemic hypotension and renal failure in obstructive jaundice-mechanistic and therapeutic aspects. J Am Soc Nephrol. 1995; 5(11):1853-1871.

4. Rege RV. Adverse effects of biliary obstruction: implications for treatment of patients with obstructive jaundice. AJR Am J Roentgenol. 1995; 164(2):287-293.

5. Song JG, Cao YF, Sun YM, Ge YH, Xu XW, Yang LQ, Liu ZQ, Song SL, Yu WF. Baroreflex sensitivity is impaired in patients with obstructive jaundice. Anesthesiology. 2009; 111(3):561-565.

6. Bomzon A, Rosenberg M, Gali D, Binah O, Mordechovitz D, Better OS, Greig PD, Blendis LM. Systemic hypotension and decreased pressor response in dogs with chronic bile duct ligation. Hepatology (Baltimore, Md). 1986; 6(4):595-600.

7. Finberg JP, Syrop HA, Better OS. Blunted pressor response to angiotensin and sympathomimetic amines in bile-duct ligated dogs. Clinical science (London, England : 1979). 1981; 61(5):535-539.

8. Bevan M, Bancroft I, Bent E, Love K, Goodman H, Dean C, Bergkamp R, Dirkse W, Van Staveren M, Stiekema $\mathrm{W}$ et al. Analysis of $1.9 \mathrm{Mb}$ of contiguous sequence from chromosome 4 of Arabidopsis thaliana. Nature. 1998; 391(6666):485-488.

9. Akata T. General anesthetics and vascular smooth muscle: direct actions of general anesthetics on cellular mechanisms regulating vascular tone. Anesthesiology. 2007; 106(2):365-391. 
10. Tang DD, Anfinogenova Y. Physiologic properties and regulation of the actin cytoskeleton in vascular smooth muscle. J Cardiovasc Pharmacol Ther. 2008; 13(2):130-140.

11. Yamin R, Morgan K. Deciphering actin cytoskeletal function in the contractile vascular smooth muscle cell. J Physiol (Lond). 2012; 590(17):4145-4154.

12. Schildmeyer LA, Braun R, Taffet G, Debiasi M, Burns AE, Bradley A, Schwartz RJ. Impaired vascular contractility and blood pressure homeostasis in the smooth muscle alpha-actin null mouse. FASEB journal : official publication of the Federation of American Societies for Experimental Biology. 2000; 14(14):2213-2220.

13. Greenberg MJ, Wang CL, Lehman W, Moore JR. Modulation of actin mechanics by caldesmon and tropomyosin. Cell Motil Cytoskeleton. 2008; 65(2):156-164.

14. Barua B, Winkelmann DA, White HD, Hitchcock-DeGregori SE. Regulation of actin-myosin interaction by conserved periodic sites of tropomyosin. Proc Natl Acad Sci U S A. 2012; 109(45):18425-18430.

15. Burger A, Berendes R, Liemann S, Benz J, Hofmann A, Göttig P, Huber R, Gerke V, Thiel C, Römisch J et al. The crystal structure and ion channel activity of human annexin II, a peripheral membrane protein. J Mol Biol. 1996; 257(4):839-847.

16. Bharadwaj A, Bydoun M, Holloway R, Waisman D. Annexin A2 heterotetramer: structure and function. Int J Mol Sci. 2013; 14(3):6259-6305.

17. Babiychuk E, Palstra R, Schaller J, Kämpfer U, Draeger A. Annexin VI participates in the formation of a reversible, membrane-cytoskeleton complex in smooth muscle cells. J Biol Chem. 1999; 274(49):35191-35195.

18. Xu X, Hu H, Wang X, Ye W, Su H, Hu Y, Dong L, Zhang R, Ying K. Involvement of CapG in proliferation and apoptosis of pulmonary arterial smooth muscle cells and in hypoxia-induced pulmonary hypertension rat model. Exp Lung Res. 2016; 42(3):142-153.

19. Bitar KN. HSP27 phosphorylation and interaction with actin-myosin in smooth muscle contraction. American journal of physiology Gastrointestinal and liver physiology. 2002; 282(5):G894-903.

20. Wang Y, Xiong Z, Gong W, Zhou P, Xie Q, Zhou Z, Lu G. Expression of heat shock protein 27 correlates with actin cytoskeletal dynamics and contractility of cultured human bladder smooth muscle cells. Exp Cell Res. 2015; 338(1):39-44.

21. Meier M, King G, Clermont A, Perez A, Hayashi M, Feener E. Angiotensin AT(1) receptor stimulates heat shock protein 27 phosphorylation in vitro and in vivo. Hypertension. 2001; 38(6):1260-1265.

22. dos Remedios CG, Chhabra D, Kekic M, Dedova IV, Tsubakihara M, Berry DA, Nosworthy NJ. Actin binding proteins: regulation of cytoskeletal microfilaments. Physiological reviews. 2003; 83(2):433473.

23. Ostrowska Z, Moraczewska J. Cofilin - a protein controlling dynamics of actin filaments. Postepy Hig Med Dosw (Online). 2017; 71(0):339-351.

24. Xie X, Nie X, Wu J, Zhang F, Zhao L, Lin Y, Yin Y, Liu H, Shu Y, Miao S et al. Smooth muscle 22a facilitates angiotensin II-induced signaling and vascular contraction. J Mol Med. 2015; 93(5):547558. 
25. Zeidan A, Sward K, Nordstrom I, Ekblad E, Zhang JC, Parmacek MS, Hellstrand P. Ablation of SM22alpha decreases contractility and actin contents of mouse vascular smooth muscle. FEBS letters. 2004; 562(1-3):141-146.

26. Schreiber V, Moog-Lutz C, Regnier CH, Chenard MP, Boeuf H, Vonesch JL, Tomasetto C, Rio MC. Lasp1 , a novel type of actin-binding protein accumulating in cell membrane extensions. Mol Med. 1998; 4(10):675-687.

27. Wang N, Stamenovic D. Mechanics of vimentin intermediate filaments. J Muscle Res Cell Motil. 2002; 23(5-6):535-540.

\section{Tables}

Table 1. Demographic Data

\begin{tabular}{lll}
\hline & Control & Obstructive Jaundice \\
\hline $\mathrm{n}$ & 10 & 9 \\
Sex, $\mathrm{M} / \mathrm{F}$ & $6 / 4$ & $5 / 4$ \\
Age, $\mathrm{yr}$ & $53.5 \pm 3.63$ & $55.8 \pm 3.38$ \\
Height, $\mathrm{cm}$ & $164.8 \pm 9.16$ & $161.7 \pm 8.27$ \\
Weight, kg & $61.76 \pm 11.59$ & $59.71 \pm 10.95$ \\
$\mathrm{BSA}, \mathrm{m} 2$ & $1.68 \pm 0.20$ & $1.63 \pm 0.19$ \\
Total bilirubin, $\mu \mathrm{M}$ & $12.2 \pm 0.80$ & $162.6 \pm 28.41^{*}$ \\
Bile acids, $\mu \mathrm{M}$ & $6.6 \pm 0.45$ & $81.5 \pm 13.89^{*}$ \\
\hline
\end{tabular}

Table 2: Identification results of proteins differentially expressed in obstructive jaundice and non-jaundice patients (MALDI-TOF MS) 


\begin{tabular}{|l|l|l|}
\hline protein name & Accession NO. & Fold change (T/N) \\
\hline Actin, aortic smooth muscle & P62736 & 1.56782 \\
\hline Actin, gamma-enteric smooth muscle & P63267 & 1.47153 \\
\hline Actin, cytoplasmic 2 & P63261 & 1.84219 \\
\hline Tropomyosin beta chain & P07951 & 1.29052 \\
\hline Transgelin & Q01995 & -1.23158 \\
\hline Vimentin & P08670 & 2.15428 \\
\hline Annexin A2 & P07355 & 1.51842 \\
\hline Annexin A5 & P08758 & 1.36364 \\
\hline Gelsolin & P06396 & 1.20617 \\
\hline Cofilin-1 & P23528 & 1.35534 \\
\hline LIM and SH3 domain protein 1 & Q14847 & -1.68030 \\
\hline Sorbin and SH3 domain-containing protein 2 & $\mathrm{Q} 94875$ & -1.41926 \\
\hline Keratin, type I cytoskeletal 9 & P35527 & 1.20084 \\
\hline Prelamin-A/C & P02545 & -1.30005 \\
\hline Delta(3,5)-Delta(2,4)-dienoyl-CoA isomerase & $\mathrm{Q} 13011$ & -1.45960 \\
\hline Galactokinase & P51570 & 1.86176 \\
\hline Pyruvate kinase PKM & P14618 & 1.20084 \\
\hline Protein AMBP & P02760 & 1.42851 \\
\hline Glutathione S-transferase P & P09211 & 1.46583 \\
\hline Fibrinogen beta chain & P02675 & -1.36779 \\
\hline Biglycan & P21810 & -1.29570 \\
\hline Heat shock protein beta-1 & P04792 & 1.34520 \\
\hline Polymerase I and transcript release factor & Q6NZ12 & 1.75672 \\
\hline Ras suppressor protein 1 & Q15404 & -2.15990 \\
\hline
\end{tabular}

\section{Figures}
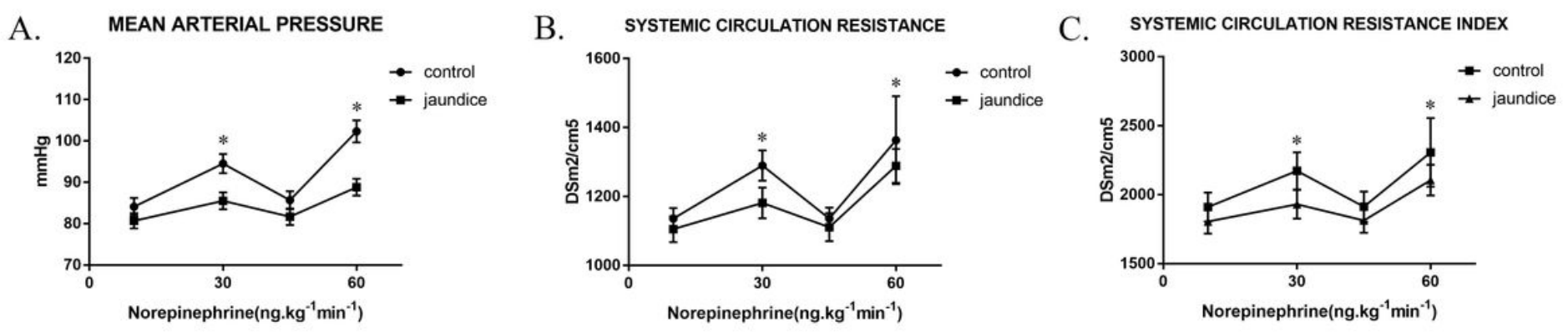

Figure 1

Vascular reactivity after agent administration. A. Measured MAP values in $\mathrm{OJ}$ and non-OJ patients $(P<0.05$, two-way ANOVA with post hoc Bonferroni correction). B. Measured SVR in OJ and non-OJ patients ( $P>0.05$, two-way ANOVA with post hoc Bonferroni correction). C. Measured SVRI in OJ and nonOJ patients ( $P>0.05$, two-way ANOVA with post hoc Bonferroni correction). 


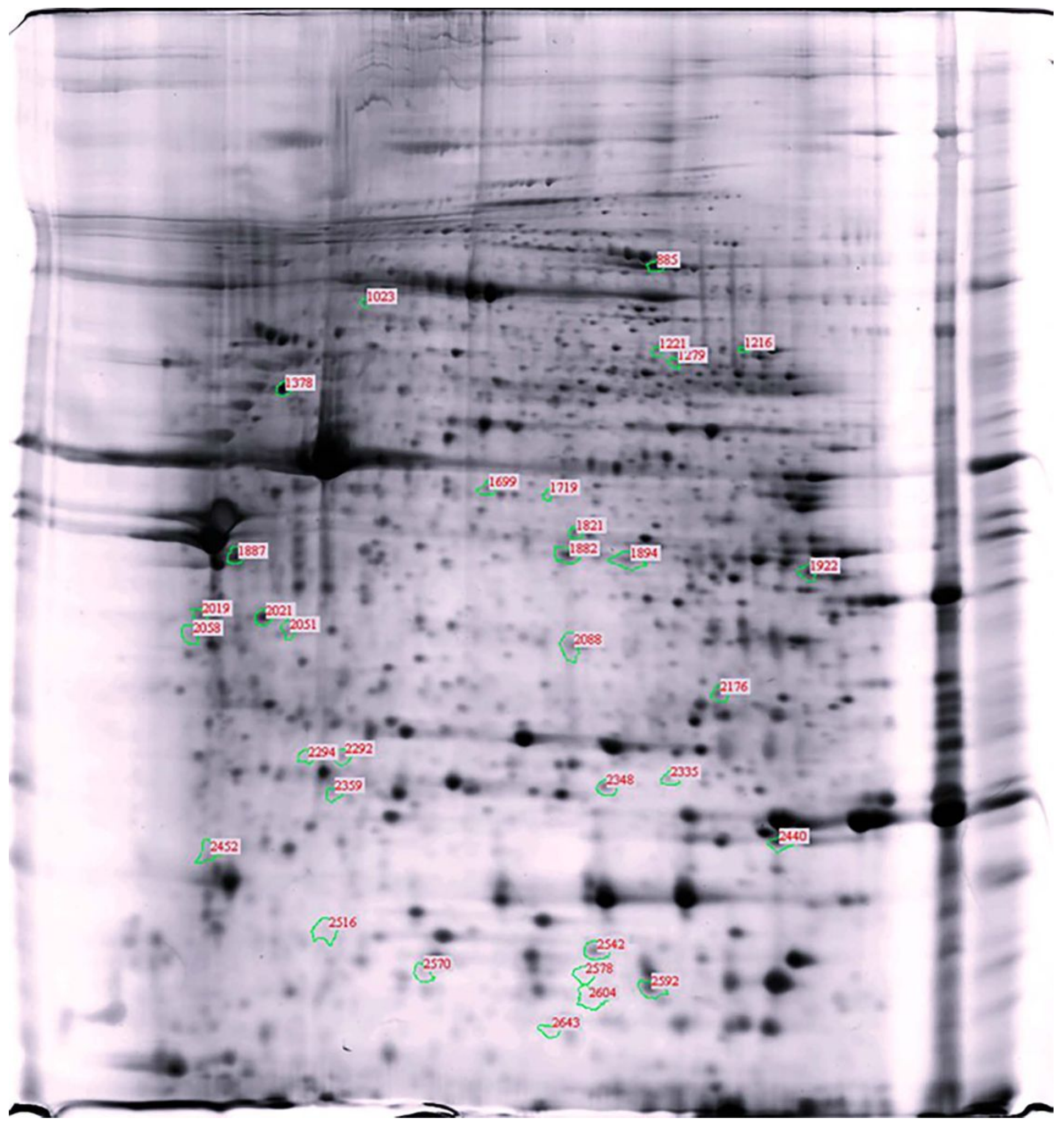

Figure 2

Differentially expressed protein spots identified by DIGE analysis. The annotated proteins were either upregulated or downregulated in patients with obstructive jaundice in comparison with control patients. (colored figured). 


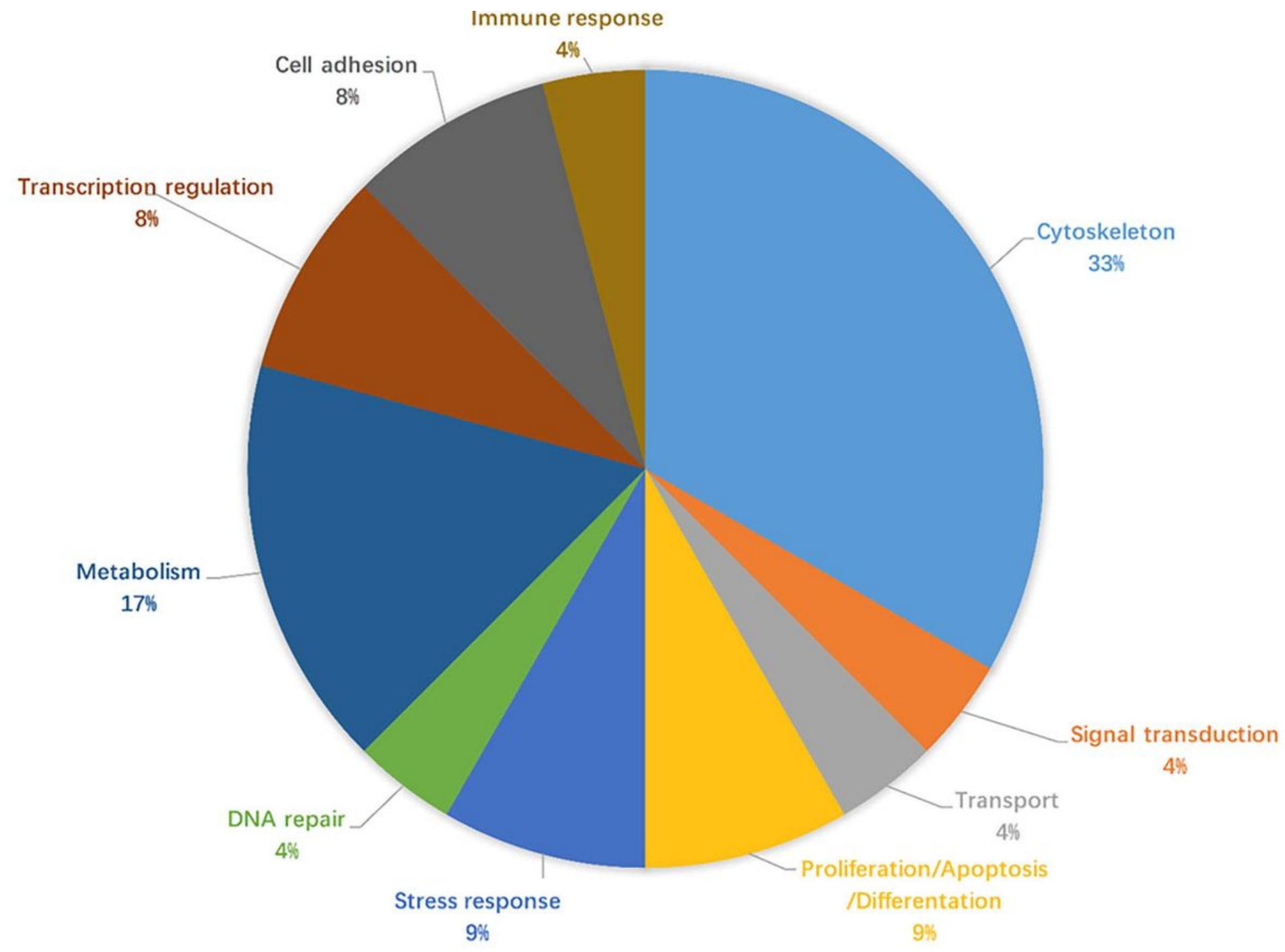

Figure 3

Functional annotation of differentially expressed proteins between obstructive jaundice and non-jaundice patients. 


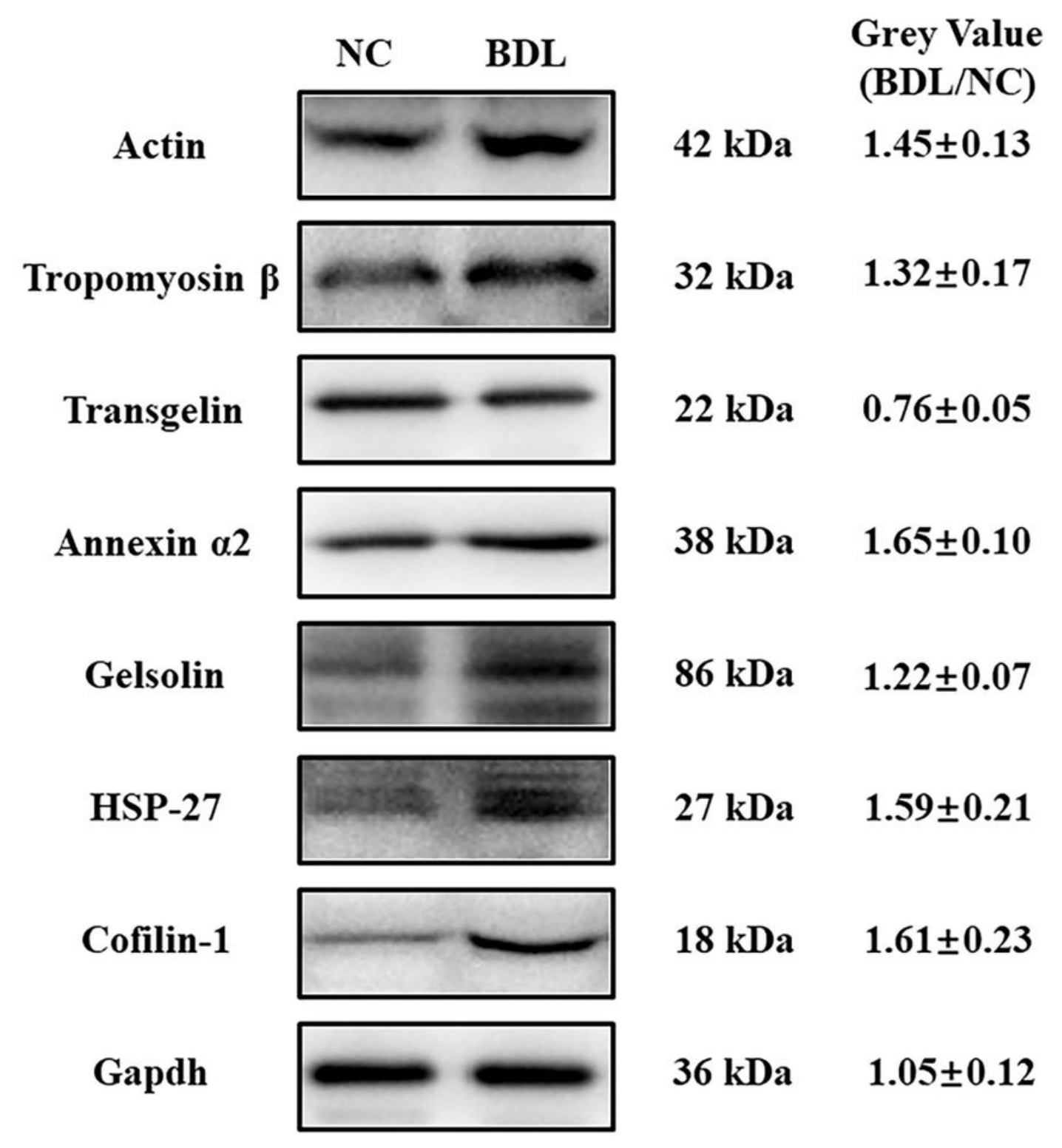

Figure 4

Confirmation of seven actin or actin-related proteins in the cytoskeleton signaling pathway. 